\title{
A root cause analysis of increasing caesarean section rates in a tertiary care private hospital in North India
}

\author{
Bela Makhija*, Deepika Verma, Asif Mustafa
}

Department of Obstetrics and Gynecology, Max Smart Super Specialty Hospital, New Delhi, India

Received: 21 August 2019

Accepted: 30 September 2019

\author{
*Correspondence: \\ Dr. Bela Makhija, \\ E-mail: bela.makhija@maxhealthcare.com
}

Copyright: () the author(s), publisher and licensee Medip Academy. This is an open-access article distributed under the terms of the Creative Commons Attribution Non-Commercial License, which permits unrestricted non-commercial use, distribution, and reproduction in any medium, provided the original work is properly cited.

\begin{abstract}
Background: Increase in the incidence of caesarean section is a matter of concern worldwide. Robson's criteria which is universally accepted now as a way for calculating caesarean rates takes into account only the obstetrical consideration, however, it is noteworthy that many socioeconomic and cultural factors also have a role to play. This study takes into account both Robson's criteria and common socio-cultural factors which lead to increased caesarean rates with an attempt to suggest ways to curtail this trend.

Methods: The study was a hospital based cross-sectional study at a private tertiary care hospital in New Delhi. 1200 consecutive live births after 34 weeks of gestation were analysed over a period of one year.

Results: LSCS was the most common mode of delivery 733 (61.1\%). 329 (27.4\%) had induced labour of which 260 (76.2\%) had LSCS. 333 women had elective LSCS. Rates of CDMR were 185 (25.2\%) which is very significant. As per Robson's criteria maximum number of women (318) were in group 2, of which 226 (71.1\%) underwent caesarean section.

Conclusions: High caesarean rates can be attributed to a multitude of factors. Robson's criteria are an effective way for analysis of obstetric indications. Other added factors include comorbidities, CDMR, fear of litigations, etc which were analysed.
\end{abstract}

Keywords: Caesarean delivery on maternal request, Lower segment caesarean section, Robson's criteria, Trial of labour after caesarean, Vaginal birth after caesarean section

\section{INTRODUCTION}

Caesarean section is one of the most commonly performed major surgeries in obstetric practice intended to save the mother and child, in turn, reducing maternal and perinatal mortality. ${ }^{1,2}$ Prevalence of caesarean section in USA is $29.1 \%$ and in England is $21.5 \%$. $^{3,4}$

Data from NFHS-4 states that the prevalence of CS in India is $20.1 \% .^{5}$ WHO states that no additional health benefits are associated with a section rate above $15 \%{ }^{6}$ Recent data from the National Family Health Survey 2014-15 (NFHS-4) reveals that at the all India level the rate of CS have doubled over the last decade, while in last 20 years, it has risen six times.

According to NFHS-4 data, CS rate is three times higher in private hospitals $(31.1 \%)$, as compared to public hospitals $(10 \%)$. This may be a reflection of increasing privatization, betraying a greater profit motive in the provision of healthcare facilities in recent times. ${ }^{5}$ Various other causes of increasing trend in caesarean section are higher educational levels, lower tolerance for labour pains, economically sound state of family, presence of more private hospitals, higher rate of litigation. ${ }^{7}$ 
Defensive obstetrics is another common reason for high rates of CS. It has been observed that $82 \%$ of physicians performed $\mathrm{CS}$ to avoid negligence claims. It is this increase in burden of litigation that prevents the obstetrician from taking any risk with either the mother or her baby. ${ }^{8}$

The study was undertaken to critically analyse most factors including social factors responsible for the increasing rates of caesarean sections because on extensive research of literature we were unable to get any conclusive studies on the detailed analysis of the subject. No comparison is being drawn between various indications for CS- we did a root cause analysis of the various reasons for which caesareans are being done with a view to suggest ways to curtail this trend. This study was done to get an in depth understanding of the various factors to enable us to strategize regarding methods to bring down this rising trend.

\section{METHODS}

It was a hospital based cross-sectional study conducted on 1200 women over a period of one year from December 2017 to November 2018 in tertiary care private hospital in New Delhi, India.

\section{Inclusion criteria}

- All patients admitted in labour room within 1-year period at more than 34 weeks of gestation were included in this study.

\section{Exclusion criteria}

- Deliveries at $33+6$ weeks or earlier and intrauterine fetal death were excluded from the study.

The data was compiled according to Robson's TGCS (ten-group classification system) of caesarean sections. Data was obtained from labour room birth register records. The percentage of total caesarean delivery was calculated as per Robson's criteria. Rate of CDMR, and VBAC were also calculated.

In addition to Robson's criteria, all relevant obstetric information pertaining to co- morbidities, reasons for CDMR, reasons for refusing TOLAC, etc, was entered on a proforma and then transferred into Microsoft excel sheet, and analysis was carried out on entire dataset. Interview with all consultants in the hospital was done at the end of the study to find out what prompted most of them to do LSCS.

\section{Statistical analysis}

Data was analysed and statistically evaluated using SPSS software, version 20 (Chicago II, USA). ${ }^{9}$ Quantitative data was expressed in mean and standard deviation while qualitative data were expressed in percentage. Statistical differences between the proportions were tested by chisquare test or Fisher's exact test. ' $p$ ' value less than 0.05 was considered statistically significant.

\section{RESULTS}

Most of the pregnant women were in the age group of 2130 years $(49.5 \%)$ followed by 31 - 40 years $(46.9 \%)$. Mean age of the pregnant women in the study was $30.58 \pm 4.61$ years

Majority of women admitted in our hospital were graduates and above $71.4 \%$. Primigravida were 656 (54.6\%). Total term pregnancies were 1122 (93.5\%). $1098(91.5 \%)$ women were booked i.e. they had minimum of 3 antenatal visits in our hospital. 34 women had twin pregnancy (2.8\%). 1111 (92.6\%) presentation were cephalic. $89(7.4 \%)$ were either breech, or shoulder. In $1175(97.9 \%)$ women, lie was longitudinal, whereas 16 $(1.3 \%)$ women had transverse lie, and $9(0.8 \%)$ women had oblique lie.

In the group of women who had spontaneous onset of labour, the LSCS rate was $18.7 \%$ (101/538). Patients who were induced had a caesarean rate as high as $76.2 \%$ (250/329). This increase in caesarean rate after induction was statistically very significant. $333(27.8 \%)$ women had elective caesarean without onset of labour- this included absolute indications as well as caesarean on maternal request (Table 1).

Caesarean emerged as the commonest mode of delivery $(\mathrm{n}=733 ; 61.1 \%)$ followed by spontaneous vaginal deliveries 409 (34.1\%). $58 \quad(4.8 \%)$ women had instrumental delivery (forceps + vacuum) during this study period. There were 1232 live births as 33 were twins. LSCS rates were higher in induced cases as compared to those who had spontaneous onset of labour, i.e. group 1 (Table 2).

In the study, most women were in Robson's group 2 and $226(71.7 \%)$ of them had caesareans. $34.9 \%$ subjects of Group 1 had caesareans. These rates in both groups were very high compared to WHO's Robson's guidelines implementation manual which advocates $<10 \%$.

$63.02 \%$ had primary caesarean section. Most common indication for caesarean among these women was foetal distress $(25.7 \%$ ), followed by CDMR $20.1 \%$. Medical disorders like PIH, GDM accounted for $3.7 \%$ caesarean. APH and placenta previa together contributed $3.8 \%$ for primary caesarean (Table 3 ).

Maternal request for caesarean was significantly high at $20.1 \%$. Around $40 \%$ had repeat caesarean section. Most common indication for a repeat caesarean section was CDMR, followed by CPD (Table 4). 
Table 1: Onset of labor.

\begin{tabular}{|lllll|}
\hline Onset of labor & $\begin{array}{l}\text { Number of } \\
\text { women }\end{array}$ & $\begin{array}{l}\text { Number of LSCS in each } \\
\text { group }\end{array}$ & $\begin{array}{l}\text { Total \% } \\
\text { in group }\end{array}$ & $\begin{array}{l}\text { \% LCS in } \\
\text { each group }\end{array}$ \\
\hline Spontaneous & 538 & 101 & $44.8 \%$ & $18.7 \%$ \\
\hline Induced & 329 & 250 & $27.4 \%$ & $76.2 \%$ \\
\hline LSCS without induction & 333 & 333 & $27.8 \%$ & $100 \%$ \\
\hline
\end{tabular}

Table 2: Robson's groupwise distribution.

\begin{tabular}{|c|c|c|c|c|}
\hline \multirow[t]{2}{*}{ Robson's Group } & \multicolumn{2}{|c|}{$\begin{array}{l}\text { Women in } \\
\text { each group }\end{array}$} & \multirow{2}{*}{$\begin{array}{l}\text { No. of CS in } \\
\text { each group } \\
\%\end{array}$} & \multirow{2}{*}{$\begin{array}{l}\text { Group cesarean } \\
\text { rate } \\
\%\end{array}$} \\
\hline & No. & $\%$ & & \\
\hline Nulliparous, single cephalic, $>37$ weeks in spontaneous labor & 249 & $20.8 \%$ & 87 & $34.9 \%(87 / 249)$ \\
\hline $\begin{array}{l}\text { Nulliparous, single, cephalic, }>37 \text { weeks induced or cesarean } \\
\text { before labor }\end{array}$ & 318 & $26.5 \%$ & 226 & $71.1 \%(226 / 318)$ \\
\hline $\begin{array}{l}\text { Multiparous, excluding previous CS, single, cephalic, >37 } \\
\text { weeks in spontaneous labor }\end{array}$ & 125 & $10.4 \%$ & 14 & $11.2 \%(14 / 125)$ \\
\hline $\begin{array}{l}\text { Multiparous, excluding previous CS, >37 weeks, single, } \\
\text { cephalic, induced or cesarean before labor }\end{array}$ & 87 & $7.25 \%$ & 24 & $27.5 \%(24 / 87)$ \\
\hline Previous cesarean, single, cephalic, $>37$ weeks & 269 & $22.4 \%$ & 248 & $92.2 \%(248 / 269)$ \\
\hline All nulliparous breeches & 30 & $2.5 \%$ & 27 & $90 \%(27 / 30)$ \\
\hline All multiparous breeches, including previous CS & 21 & $1.75 \%$ & 20 & $95.2 \%(20 / 21)$ \\
\hline All multiple pregnancy & 36 & $3 \%$ & 33 & $91.6 \%(33 / 36)$ \\
\hline All pregnancies with abnormal lie & 15 & $1.25 \%$ & 15 & $100 \%(15 / 15)$ \\
\hline All single, cephalic <36 weeks, including previous CS & 50 & $4.17 \%$ & 39 & $78 \%(39 / 50)$ \\
\hline Total & 1200 & $100 \%$ & $100 \%$ & \\
\hline
\end{tabular}

Table 3: Indications of primary caesarean sections.

\begin{tabular}{|lll|}
\hline Indications & No. & $\%$ \\
\hline Absolute indications (n=108) & & \\
\hline CPD & 61 & $13.2 \%$ \\
\hline Placenta previa & 6 & $1.2 \%$ \\
\hline Transverse / oblique Lie & 13 & $2.8 \%$ \\
\hline $\begin{array}{l}\text { Multiple pregnancy (first baby } \\
\text { other than cephalic) }\end{array}$ & 28 & $6.0 \%$ \\
\hline Relative indications (n=261) & & \\
\hline Fetal distress & 119 & $25.7 \%$ \\
\hline Non progress of labor & 30 & $6.5 \%$ \\
\hline Failed induction & 35 & $7.6 \%$ \\
\hline Severe IUGR & 8 & $1.7 \%$ \\
\hline APH & 12 & $2.6 \%$ \\
\hline Primi breech & 36 & $7.7 \%$ \\
\hline Medical disorders & 17 & $3.7 \%$ \\
\hline Others & 4 & $0.9 \%$ \\
\hline CDMR & 93 & $20.1 \% *$ \\
\hline Total & $\mathbf{4 6 2}$ & \\
\hline
\end{tabular}

*Primiparous women had a CDMR rate of $20.1 \%$, while $5.1 \%$ was due to women with previous LSCS insisting upon caesarean without any indication, unwilling for TOLAC.

CDMR (caesarean delivery on maternal request) contributed $25.2 \%$ in the total caesarean rate. Of these, $57 \%$ demanded caesarean after onset of labour due to inability to tolerate labour pains (Table 5).
Table 4: Indications of repeat caesarean section.

\begin{tabular}{|lll|}
\hline Indications & No. & $\%$ \\
\hline Absolute indications (n=69) & \multicolumn{1}{l|}{} \\
\hline CPD & 38 & $14 \%$ \\
\hline Placenta previa & 3 & $1.1 \%$ \\
\hline 2 or more Cs & 22 & $8.1 \%$ \\
\hline Transverse / oblique lie & 2 & $0.7 \%$ \\
\hline $\begin{array}{l}\text { Multiple pregnancy(first } \\
\text { baby other than cephalic) }\end{array}$ & 4 & $1.4 \%$ \\
\hline Relative indication (n=107) & & \\
\hline Fetal distress & 20 & $7.4 \%$ \\
\hline Non progress of labor & 7 & $2.6 \%$ \\
\hline Failed induction & 1 & $0.4 \%$ \\
\hline Severe IUGR & 5 & $1.8 \%$ \\
\hline APH & 2 & $0.7 \%$ \\
\hline Breech & 11 & $4.0 \%$ \\
\hline Medical disorders & 9 & $3.3 \%$ \\
\hline Scar tenderness/ thinning & 35 & $12.9 \%$ \\
\hline $\begin{array}{l}\text { Short ICP (interconceptional } \\
\text { period) }\end{array}$ & 5 & $1.8 \%$ \\
\hline Others & 12 & $1.0 \%$ \\
\hline CDMR & 95 & $35 \%$ \\
\hline Total & $\mathbf{2 7 1}$ & \\
\hline
\end{tabular}

(Table 6) Majority of the women had hypothyroidism, mostly gestational followed by GDM, which led to their induction and an increasing number of caesareans. 47/75 
Table 5: Reasons for CDMR.

\begin{tabular}{|llll|}
\hline $\begin{array}{l}\text { Reasons } \\
\text { Fear of labor pains }\end{array}$ & Number of women & Percentage & $\begin{array}{l}\text { Contribution to } \\
\text { overall cs } \%\end{array}$ \\
\hline a) Patients who demanded cesarean after onset of labor & $106 / 185$ & $57 \%$ & 14.4 \\
\hline b) Patients who demanded cesarean before onset of labor & $21 / 185$ & $11.4 \%$ & 2.86 \\
\hline Anxiety for well being of baby & $30 / 185$ & $16.2 \%$ & 4.09 \\
\hline Mahurat cesarean (astrological reasons) & $28 / 185$ & $15.1 \%$ & 3.83 \\
\hline
\end{tabular}

Table 6: Medical disorders associated in addition to primary indication in present pregnancy.

\begin{tabular}{|llll|}
\hline Medical disorders & Number of women & $\%$ in total study group (n=1200) & CS\% in each group \\
\hline GDM & 75 & 6.25 & $62.66 \%(47 / 75)$ \\
\hline PIH & 51 & 4.25 & $52.9 \%(27 / 51)$ \\
\hline IHCP & 73 & 6.08 & $49.3 \%(36 / 73)$ \\
\hline Heart disease & 5 & 0.42 & $80 \%(4 / 5)$ \\
\hline Renal disease & 1 & 0.08 & $100 \%(1 / 1)$ \\
\hline Thyroid disorders & 124 & 10.33 & $61.3 \%(76 / 124)$ \\
\hline BMI $>30$ pre-pregnancy & 36 & 3 & $63.89 \%(23 / 36)$ \\
\hline Other medical disorders & 40 & 3.33 & $67.5 \%(27 / 40)$ \\
\hline
\end{tabular}

Table 7: Rates of caesarean section in various studies.

\begin{tabular}{|ll|}
\hline Yearwise list of various studies & Cesarean rates \\
\hline Shillang Liu et al & \\
\hline Betran AP et al $^{13}$ & $22.1 \%$ \\
\hline Barber EL et al $^{15}$ & $35.4 \%$ \\
\hline Kazmi T et al $^{16}$ & $36.5 \%$ \\
\hline Seffah JD et al & $20.3 \%$ \\
\hline Dhodapkar SB et al $^{10}$ & $40 . \%$ \\
\hline Liu Yet al $^{18}$ & $32.6 \%$ \\
\hline Ramesh B et al & \\
\hline Koteshwara S & $54.9 \%$ \\
\hline Balmur SK et al & $52.6 \%$ \\
\hline Present study in $2018-19$ & $37.6 \%$ \\
\hline
\end{tabular}

*This table shows a progressive increase in caesarean rate over the years, however it is worth noting that most of these studies are in government setups, while ours was in a private hospital.

Table 8: Comparison of CS rates (as per Robson's) in present study with previous studies.

\begin{tabular}{|c|c|c|c|c|c|c|c|}
\hline $\begin{array}{l}\text { Robson's } \\
\text { group }\end{array}$ & $\begin{array}{l}\text { Present } \\
\text { study }\end{array}$ & $\begin{array}{l}\text { Koteshwara } \\
\text { S et al }\end{array}$ & $\begin{array}{l}\text { Ramesh B et } \\
\text { al }^{19}\end{array}$ & $\begin{array}{l}\text { Yadav RG et } \\
\text { al }^{22}\end{array}$ & $\begin{array}{l}\text { Betran } \\
\text { AP et } \\
\text { al }^{14}\end{array}$ & $\begin{array}{l}\text { Jacob KJ } \\
\text { et } \mathbf{a l}^{23}\end{array}$ & $\begin{array}{l}\text { Dhodapkar SB } \\
\text { et al }{ }^{17}\end{array}$ \\
\hline 1 & $34.9 \%$ & $18.6 \%$ & & $37.62 \%$ & $18.3 \%$ & & \\
\hline 2 & $71.1 \%$ & $32.2 \%$ & $28.1 \%$ & $47.28 \%$ & $15.3 \%$ & & \\
\hline 3 & $11.2 \%$ & & & $15 \%$ & & & $5.9 \%$ \\
\hline 4 & $27.5 \%$ & & & $34.74 \%$ & & & \\
\hline 5 & $92.2 \%$ & $28.9 \%$ & $12.2 \%$ & & $26.7 \%$ & $61.5 \%$ & $40.1 \%$ \\
\hline 6 & $90 \%$ & & & & & & $100 \%$ \\
\hline 7 & $95.2 \%$ & & & & & & $100 \%$ \\
\hline 8 & $91.6 \%$ & & & & & & \\
\hline 9 & $100 \%$ & & & & & & $100 \%$ \\
\hline 10 & $78 \%$ & & & & & & \\
\hline
\end{tabular}


5 women had heart disease like septal defects, RHD, global hypokinesis, CHD at admission. 4/5 had caesarean sections. Only 1 woman admitted had renal disorder, and she had caesarean. $63.89 \%$ of women who were obese (pre pregnancy BMI >30) had caesarean.

Table 9: Reasons for increasing caesarean sections.

\begin{tabular}{|ll|}
\hline Reasons for increasing LSCS & $\%(\mathrm{n}=20)$ \\
\hline Fear of litigation & $90 \%(18 / 20)$ \\
\hline $\begin{array}{l}\text { Fear of losing patients to another } \\
\text { practitioner }\end{array}$ & $25 \%(5 / 20)$ \\
\hline Convenient time & $25 \%(5 / 20)$ \\
\hline Financial gain & $0 \% *$ \\
\hline
\end{tabular}

*We have the same pay out for the doctors irrespective of whether it is a LSCs or NVD. It emerged from this study that fear of litigation is the single largest cause for obstetricians not willing to take any risk, thus, even when the payout to the doctors remain the same, the rate does not decrease.

There were many patients who had more than one medical disorder during pregnancy. In most cases, medical disorders were not the primary indications for caesarean. Hence co morbidities were a contributing factor for decision for LSCS.

\section{DISCUSSION}

In the present study mean age of the pregnant women was $30.58 \pm 4.61$ years which may be due to increasing trend for late marriages, especially, amongst professional and educated women. Most of the women in our study were graduates or more $(71.4 \%)$. The study is in stark contrast to an earlier study done by Seffah JD in which 414 $(9.0 \%)$ women had not received any formal education. ${ }^{10}$

More than half $(54.6 \%)$ pregnant women were primigravida, $91.5 \%$ were booked pregnancy and $93.5 \%$ had >37 weeks of gestation at time of admission. A similar study by $\mathrm{R}$ Subhashini et al reported that $72.6 \%$ women were multigravida, $86.09 \%$ were booked and $74.32 \%$ were $>37$ weeks of gestation at time of admission. $^{11}$

In spontaneous onset of labour group CS rate was $18.7 \%$ while in induction group it was $76.2 \%$. In the study, overall caesarean rates among the booked was $60.4 \%$ (663/1200), and among the unbooked it was 68.6\%. This difference in CS rate was statistically significant. As per a study by Amita Ray et al, the CS rate for unbooked cases was $36.3 \%$ (227/624 live births) and that of booked cases was $24.3 \%$ (247/1016 live births). ${ }^{12}$

The overall caesarean section rate in the study is $61.1 \%$ which was very high compare to other studies (Table 7). A complete analysis was done as per Robson's criteria, other studies only show certain important groups (Table 8).
In a study by Agarwal $\mathrm{M}$ et al, in a low resource setting, increase in the primary caesarean rate was due to increase in incidence of foetal distress $(9.2 \%)$ and NPOL $(2.4 \%) .{ }^{24}$ $\mathrm{R}$ Subhashini et al concluded that a major cause for elective CS was CPD, 23.08\%. ${ }^{11,25}$ This was similar to the study by B. S. Dhillon et al, where the incidence of CPD was $52.9 \%$ in both these studies incidence of CPD was much higher than in the study.

IHCP was found in 73 women. Of these women 36 had CS. However, IHCP was not the primary indication for doing CS unless bile acid levels were $>40$. In a study by CF Rosales, et al median gestation at delivery of patients with IHCP, was 37 weeks (32 - 40), 54 (86\%) women were induced. ${ }^{26}$ Of these, $4(7 \%)$ had CS. PIH was cause of admission in 51 women, of which $27(52.9 \%)$ had caesarean. In the study, 36 women (3\%) were obese (i.e. pre pregnancy BMI >30) and majority, (23/36) 63.89\% had caesarean. Luiz Carlos Seligman et al, concluded that obesity was present in $308(6.9 \%)$ patients. Caesarean delivery was performed in $164(53.2 \%)$ obese patients. ${ }^{27}$

$\mathrm{R}$ Subhashini et al, found in their study that $22.54 \%$, (209/927) of patients having medical disorders were taken for caesarean. ${ }^{11}$ However, they had compiled all medical disorders like PIH, GDM, hypothyroidism and others like $\mathrm{Rh}$ negative pregnancy, h/o epilepsy together. In the study, aggregate of all medical disorders was $33.5 \%$. Being a tertiary care hospital, most medical disorders were well managed. Hence, medical disorders other than severe PIH were not the primary indication for caesarean in most cases. Elective caesarean deliveries are increasingly being performed for various indications that include maternal request, concern for pelvic floor injury associated with vaginal birth, and reduction of fetal injury rates. $^{28}$

It can be concluded from the study that Robson's classification can effectively be used in analysing delivering women and provides more clear and valuable information regarding the mode of delivery. According to the study, the primary and repeat CS rates should be analysed separately so as to understand factors responsible for growing CS rates which would help us to control it. Studies worldwide have pointed out the increasing labour inductions leading to more caesareans. Robson 10 - group classification provides easy way in collecting information about CS rates. Applying the classification helps to identify broad categories of women who can be targeted to reduce raising caesarean rates. By further analysing causes contributing to $\mathrm{CS}$ in major groups (1, 2, and 5) and formulating specific protocols like having a strict VBAC protocol, and protocols for reducing primary caesarean, which can reduce overall CS rates.

Interview with consultants were conducted to find the reasons leading to LSCS (Table 9). 


\section{CONCLUSION}

The overall CS rates in the study are high as compared to international studies. Reasons for this in the study are- the average maternal age is rising, and older women, especially nulliparas, have a higher risk of caesarean delivery. (older primiparous, more primiparous). Higher education and better socio-economic levels, hence more demand for caesarean (too posh to push) and also the potential of these patients for litigation due to greater awareness and ability to withstand the cost of litigation. (greater awareness, greater litigation. Higher rates of labour induction, especially among nulliparas raises the caesarean delivery rate.

The use of electronic fetal monitoring is widespread. This practice is associated with an increased caesarean delivery rate compared with intermittent fetal heart rate auscultation. Genuine fetal distress accounts for only a minority of all caesareans. In many more cases, concern for an abnormal or "non-reassuring" fetal heart rate tracing prompts caesarean delivery. Most fetuses presenting by breech are now delivered by caesarean. The frequency of operative vaginal delivery has declined, partly due to risks involved and partly due to lack of training.

Malpractice litigation related to injury during spontaneous or operative vaginal delivery continues to contribute to the present caesarean delivery rate. Obesity, which is a caesarean delivery risk, has reached epidemic proportions and contributing to non progress of labour with resultant caesareans. Assisted reproductive technology is more widely used than in the past and is associated with greater caesarean delivery rates.

\section{Recommendations}

Regular caesarean audits in every hospital to decrease the primary caesarean rate. Limit inductions, they should be more judicious, after opinion of at least 2 obstetricians. Educational and motivational antenatal programme which stresses advantages of natural childbirth, creates awareness of disadvantages and medical repercussions of caesarean, dispels the misconception of caesarean being pain free.

Calculate BMI of all patients at initial visit, discourage excessive weight gain during antenatal visits. Adequate counselling and encourage TOLAC, have proper protocols for the same. Regular training of labour room staff in CTG monitoring and interpretation to avoid false alarms and unnecessary caesareans. Payout to obstetricians should encourage normal delivery rather than caesarean.

Incentives and recognition of obstetricians with best normal delivery rates. Last but not the least imminent need both by institutions and insurance agencies to protect obstetricians from unwarranted litigations as fear of litigations is the biggest cause for obstetricians not wanting to take any risk.

\section{ACKNOWLEDGMENTS}

Authors would like to thank all the participants for their support support during study.

Funding: No funding sources

Conflict of interest: None declared

Ethical approval: The study was approved by the Institutional Ethics Committee

\section{REFERENCES}

1. Tampakoudis P, Assimakopoulos E, Grimbizis G, Zafrakas M, Tampakoudis G, Mantalenakis S. Cesarean section rates and indications in Greece: data from a 24-year period in a teaching hospital. Clin Experim Obst Gynecol. 2004;31(4):289-92.

2. Lee SI, Khang YH, Lee MS. Women's attitudes toward mode of delivery in South Korea: a society with high cesarean section rates. Birth. 2004;31(2):108-16.

3. Martin JA, Hamilton BE, Sutton PD, Ventura SJ, Menacker F, Kirmeyer S, Munson ML. Births: final data for 2005. National Vital Statistics Reports. 2007;56(6):1-3.

4. Thomas J, Callwood A, Brocklehurst P, Walker J. The national sentinel caesarean section audit. Int $\mathbf{J}$ Obst Gynaecol. 2000;107(5):579-80.

5. Marathe S, Mukadam R. Profiteering hospitals are driving alarming rise in $\mathrm{C}$-section deliveries in India. Available at http:// rchiips.org/ NFHS/ factsheet _NFHS-4.shtml. Accessed on $12^{\text {th }}$ January 2019.

6. Belizán JM, Showalter E, Castro A, Bastian H, Althabe F, Barros FC, et al. Rates and implications of caesarean sections in Latin America: ecological study Commentary: all women should have a choiceCommentary: increase in caesarean sections may reflect medical control not women's choice Commentary: "health has become secondary to a sexually attractive body". British Med J. 1999;319(7222):1397-402.

7. NHS Institute for innovation and improvement 2006. Delivering quality and value focus on: caesarean section. Available at https:// www. Qualitasc onsortium. com/i ndex. cfm/ reference-material/ delivering -value -quality/focus-on-csection/. Accessed on 12 January 2019.

8. Sexual and reproductive health. Department of Reproductive Health and Research (RHR) including the Special Programme HRP: A systematic review of the Robson Classification for caesarean section. WHO. Available at http://www.who.int/reproductivehealth/topics/matern al_perinatal/robson-classification/en/ Aceessed on 15 March 2019.

9. IBM. IBM SSPS software. IBM Corp (Released 2011). IBM SPSS Statistics for Windows, Version 
20.0. Armonk, NY: IBM Corp. Available at www.ibm.com/products/ssps-statistics. Accessed on 14 March 2019.

10. Seffah JD, Bonsaffoh AK. Vaginal birth after a previous caesarean section: current trends and outlook in Ghana. J West Afr Col Surg. 2014;4(2):1.

11. Subhashini R, Uma N. Changing trends in Cesarean delivery. IAIM. 2015;2(3):96-102.

12. Ray A, Jose S. Analysis of caesarean-section rates according to Robson's ten group classification system and evaluating the indications within the groups. Int J Reprod Contra Obst Gynecol. 2017;6(2):447-51.

13. Liu S, Russen D, Joseph KS, Liston R, Kramer MS, Wen SW, et al. Recent trends in cesarean delivery rates and indications for cesarean delivery in Canada. J Obstet Gynaecol Can. 2004;26(8):735-42.

14. Betran PA, Gulmezoglu AM, Robson M, Merialdi M, Souza PJ, Widmer M, et al. WHO global survey on maternal and perinatal health in latin America: classifying cesarean sections. Reprod Health. 2009;6:18.

15. Emma L, Lundsberg L, Belanger K, Pettker VM, Funai EF, Illuzzi JL. Contributing indications to rising cesarean delivery rates. Obstet Gynecol. 2011:118(1):29-38.

16. Kazmi T, Saiseema S, Khan S. Analysis of cesarean section rate- according to Robson's 10-group classification. Oman Med J. 2012;27(5):415-7.

17. Dhodapkar SB, Bhairavi S, Daniel M, Chauhan RC. Analysis of cesarean sections according to Robson's ten-group classification system at a tertiary care teaching hospital in south India. Int $\mathrm{J}$ Reprod Contracept Obstet Gynecol. 2015;4:745-9.

18. Liu Y, Li G, Wang X, Ruan Y, Zou L, Zhang W. A descriptive analysis of the indications for cesarean section in mainland China. BMC Preg Child. 2014;14:410.

19. Ramesh B, Ravi V, Archana HK. Analysis of increasing cesarean section rates using 10 group classification system. J Evid Based Med Healthc. 2016;3(61):3323-7.

20. Koteshwara S, Sujatha MS. Analysis of cesarean section rates using Robsons ten group classification: the first step. Int $\mathrm{J}$ Reprod Contracept Obstet Gynecol. 2017;6:3481-5.
21. Kumari BS, Rao GV. Study on factors influencing caesarean section delivery in urban field practice area of Kamineni Institute of Medical Sciences, Narketpally, Nalgonda, India. Int J Repro Contracep Obst Gynecol. 2017;6(7):3129-33.

22. Yadav R, Maitra N. Examining cesarean delivery rates using the robson's ten-group classification. J Obst Gynecol India. 2015;66(1):1-6.

23. Jacob KJ, Jayaprakash M, Hibina KP. TMC (Thrissur Medical College) modified Robson criteria for cesarean sections. Int J Reprod Contracept Obstet Gynecol. 2017;6(11):5038-43.

24. Agarwal M, Verma M, Garg A. Changing trends in cesarean delivery: rate and indications. Int J Reprod Contracept Obstet Gynecol. 2016;5:3522-4.

25. Dhillon BS, Chandhiok N, Bharti S, Bhatia P, Coyali $\mathrm{J}$, Das MC, et al. Vaginal birth cesarean section (VBAC) versus emergency repeat cesarean section at teaching hospitals in India: an ICMR task force study. Int J Reprod Contracept Obstet Gynecol. 2014;3(3):592-7.

26. Rosales CF, Lamb F, Ayuk P. Lower Caesarean section rates in women induced for obstetric cholestasis. Arch Dis Childhood Fetal Neonatal Edition. 2010;95(1):51-5.

27. Seligman LC, Duncan BB, Branchtein L, Gaio DS, Mengue SS, Schmidt MI. Obesity and gestational weight gain: cesarean delivery and labor complications. Revista De Saude Publica. 2006;40:457-65.

28. Cunningham FG, Leveno KJ, Bloom SL, Dash JS, Hoffman BL, Casey BM, Spongy CY; Williams Obstetrics, 25th Ed. McGraw-Hill Education; 12471252,1304 .

Cite this article as: Makhija B, Verma D, Mustafa A. A root cause analysis of increasing caesarean section rates in a tertiary care private hospital in North India. Int J Reprod Contracept Obstet Gynecol 2019;8:4531-7. 